\title{
Research on Deformation Law of Deep Foundation Pit of Station in Core Region of Saturated Soft Loess Based on Monitoring
}

\author{
Xueyan Wang, 1 Qiyu Song $\mathbb{D}^{2,3}$ and Hang Gong ${ }^{2,3}$ \\ ${ }^{1}$ School of Urban Planning and Municipal Engineering, Xi'an Polytechnic University, Xi'an, Shaanxi 710048, China \\ ${ }^{2}$ College of Civil Engineering, Xi'an University of Architecture and Technology, Xi'an, Shaanxi 710055, China \\ ${ }^{3}$ Shaanxi Key Lab of Geotechnical and Underground Space Engineering, Xi'an University of Architecture and Technology, Xi'an, \\ Shaanxi 710055, China \\ Correspondence should be addressed to Qiyu Song; 1057250488@qq.com
}

Received 20 November 2021; Revised 14 December 2021; Accepted 4 January 2022; Published 24 January 2022

Academic Editor: Dawei Yin

Copyright ( $(2022$ Xueyan Wang et al. This is an open access article distributed under the Creative Commons Attribution License, which permits unrestricted use, distribution, and reproduction in any medium, provided the original work is properly cited.

\begin{abstract}
Saturated soft loess has a large pore structure, high compressibility, low strength, fluid plastic state, and poor engineering properties. It is still one of the key problems that engineering needs to solve. In order to study the influence of deep foundation pit excavation in the saturated soft loess area on the deformation of foundation pits, the deformation laws of ground settlement, enclosure structure, and supporting axial force were clarified based on the field tests on the deformation characteristics of deep foundation pits in areas with the high-water level in saturated soft loess, combined with geological conditions and on-site construction procedures. The results indicate the following: water supply and construction process were found to be the main factor in changing the surface settlement curve of deep foundation pits in saturated soft loess; increasing the construction speed of the pit bottom floor, inverted braces, floor frame beams, and sidewall frame beams to close the structure, which is conducive to restraining the deformation of the continuous underground wall and foundation pits in similar areas. In the initial stage of support layout, the axial force of steel support tends to increase too fast or even exceed the standard control value. Therefore, a reasonable preadding axial force is an effective means to control the deformation of the continuous underground wall and the axial force of the steel support. The current research results may provide a reference for constructing deep foundation pits in similar areas.
\end{abstract}

\section{Introduction}

Loess is a kind of yellow silt sediment that is transported by wind. It is widely distributed in arid and semiarid areas in the Northwest of China, such as Shaanxi, Shanxi, and Gansu, as shown in Figure 1. It was deposited under special climate and geological conditions [1]. In this case, the naturally deposited loess has a typical structure, and loading and humidification can gradually destroy the loess structure $[2,3]$, which can cause engineering hazards $[4,5]$. One type of loess is saturated after being soaked by water and loses its collapsibility, but still has a large pore structure, with greater compressibility, lower strength, flow plasticity, and poor engineering properties, and is called saturated soft loess. During precipitation excavation in saturated soft loess areas, the surrounding ground subsidence usually occurs resulting in accidents from time to time [6-8].

Saturated soft loess is mainly distributed in Xi'an, China. In recent years, the rapid development of Xi' an has increased the scale of foundation pit excavation in saturated soft loess areas. Due to the complexity and uncertainty of the site conditions of deep foundation pit excavation, the existing theory cannot consider the influence of various factors on the deformation simultaneously. On the other hand, the field monitoring data reflect the comprehensive effect of various factors in the construction process. Therefore, a thorough 


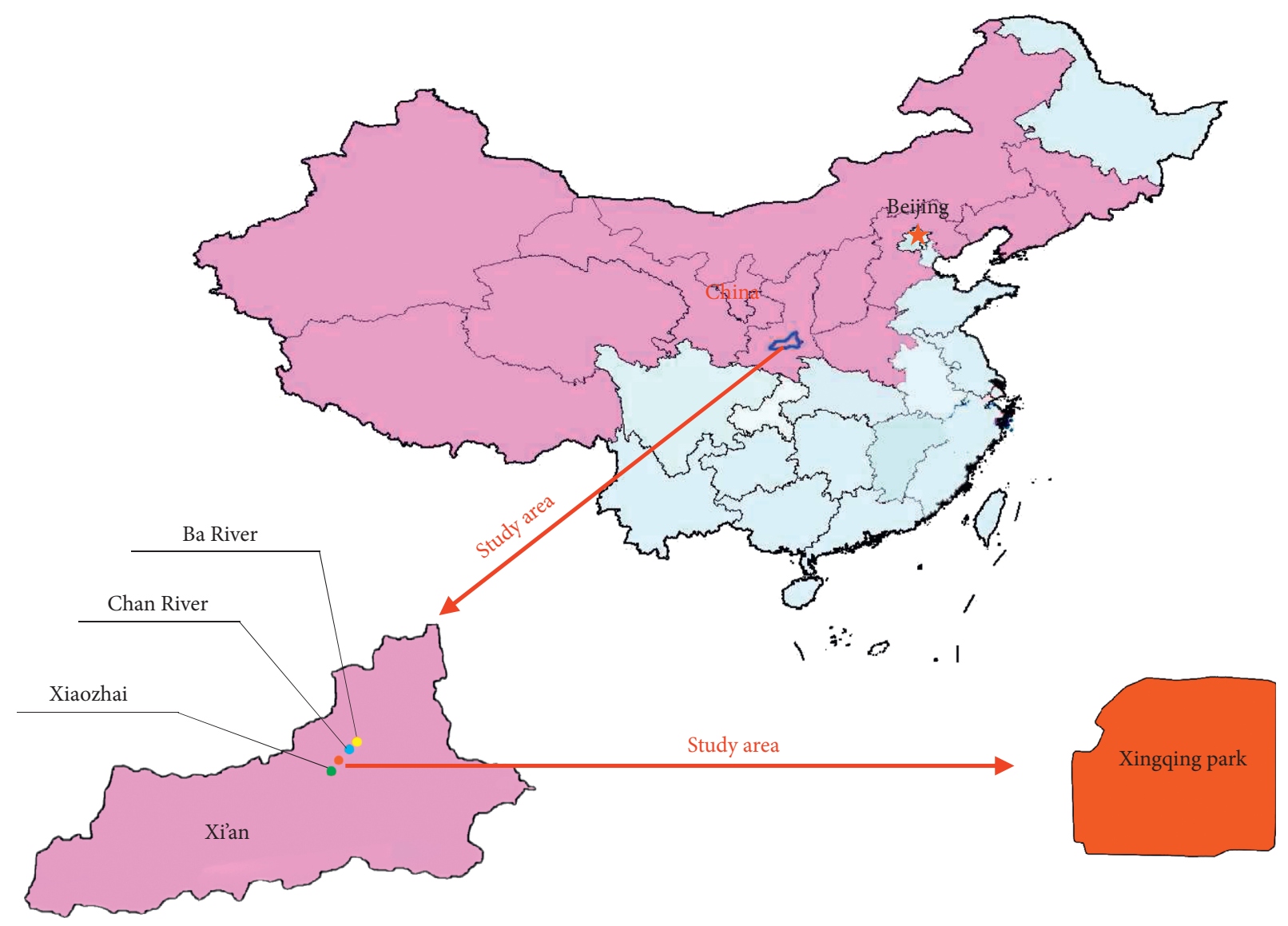

Main loess area of China

Figure 1: Main distribution of saturated soft loess in Xi'an, China.

analysis of monitoring data has become an effective way to understand deep foundation pits' deformation laws in saturated soft loess.

In recent years, many scholars have analyzed the monitoring of different types of deep foundation pits in loess and soft soil areas. Clough, Long, Moormann C, and others carried out a classification study on the deformation of different foundation pits around the world and obtained the deformation law of foundation pits during construction [9-11]; Mei and Yang analyzed the deformation characteristics and influencing factors of foundation pits in $\mathrm{Xi}$ 'an, Shanghai, Ningbo, Hangzhou, and other regions, respectively [12-14]; Zhou Yong, Ren Jianxi, Liu, Zhi, Li Zhe, Eibaz, and Wang Guohui studied and analyzed the monitoring data of pile displacement, surface settlement outside the pit, supporting axial force, and groundwater level during the excavation of the foundation pit [15-21]; Xu Jian and Zhang, respectively, compared numerical simulation and monitoring data of foundation pit excavation to analyze the deformation characteristics of foundation pit [22, 23]; Zhang and Di studied the influence of the enclosure structure on ground settlement [24, 25]; Farzi et al. [26] conducted a systematic survey of the complex geotechnical characteristics of Ahwaz, and the displacement value during construction and excavation was checked and evaluated; Wang et al. [27] analyzed the influence of soil structural changes on the horizontal displacement of the retaining structure wall, ground settlement, and adjacent subway tunnels during the excavation of the foundation pit; and Liu et al. [28] analyzed the influence mechanism of rainfall on the deformation of the soft soil foundation pit support structure.

The aforementioned research provides an effective reference for analyzing foundation pit excavation deformation law. However, there is less monitoring and analysis of deep foundation pit construction in saturated soft loess areas with high-water levels. Therefore, this article aimed to analyze and study the deformation laws between the groundwater level, the ground surface, continuous underground walls, and internal supports during the construction of deep and high-level foundation pits in saturated soft loess. The results can provide references for the excavation and the deformation prevention measures of deep foundation pits in similar saturated soft loess areas to ensure the safety and stability of the foundation pit.

\section{An Overview of the Test Section}

Saturated soft loess has the characteristics of large pore structure, high compressibility, low strength, and flow plastic state, which makes the engineering properties of saturated soft loess poor. These factors increase the construction risk of deep foundation pit excavation in saturated soft loess areas. The 
saturated soft loess in Xi'an, China is mainly distributed in Chanhe, Bahe, Xiaozhai, Xingqing Park, and other areas, as shown in Figure 1. As construction progresses, a subway in Xi'an passes through the core area of saturated soft loess in Xingqing Park. As shown in Figure 2, the deep foundation pit of the shield shaft is $28.6 \mathrm{~m}$ from the nearest Xingqing Lake. The urban area is dense, and there are old constructions around it. Therefore, the control requirements are very strict. Therefore, the deep foundation pit was selected as the test section for the on-site monitoring test.

The outer size of the deep foundation pit is $26.7 \mathrm{~m} \times 8.6 \mathrm{~m}$, and the open-cut method is adopted. The depth of the foundation pit is $30.45 \mathrm{~m}$, and the thickness of the roof covering is about $11.6 \mathrm{~m}$. According to the geological survey report, the top-down stratum of the site topography is artificial plain fill above the groundwater table, saturated soft loess below the groundwater table, ancient soil, old loess, silty clay, medium sand, and silty clay, as shown in Figure 3. Except for artificial filling, the remaining soil layers are continuously and evenly distributed throughout the site, and the layer thickness is relatively uniform. The physical parameters of soil are shown in Table 1.

\section{Test Plan}

3.1. The Foundation Pit Support Plan. The dewatering of the foundation pit for this project uses the water-stop curtain combined with the dewatering scheme in the pit. The total number of dewatering wells is 14 . There are 4 dredging wells and 10 observation wells. The foundation pit adopts the method of laying wells in the pit, as shown in Figure 4. After the underground diaphragm wall construction is completed, the foundation pit will be excavated when the dewatering meets the design requirements. After the first layer is excavated, the reinforced concrete crown beam and the supporting beam will be erected. After the concrete strength is reached, the second layer will be excavated and erected in time. The steel support will be excavated downward layer by layer.

The supporting structure of the foundation pit adopts the supporting form of a continuous underground wall combined with internal support. The continuous underground wall adopts C30 concrete, the thickness is $1 \mathrm{~m}$, the underground depth is $45 \mathrm{~m}$, and the embedded depth is $14.5 \mathrm{~m}$, as shown in Figure 4.

There are six supports in the foundation pit. The first support is made of C30 concrete. The second to sixth steel supports are supported by steel pipes with a diameter of $609 \mathrm{~mm}$ and a thickness of $16 \mathrm{~mm}$. The fifth steel support is set with inverted supports. During the continuous wall construction, the steel plate is embedded in the corresponding position, and the excavation and support are conducted during the earth excavation process. The steel support layout is shown in Figures 5.

3.2. Monitoring Plan. To prevent the excessive deformation of the foundation pit from causing safety problems, it is necessary to monitor the surrounding environment, the

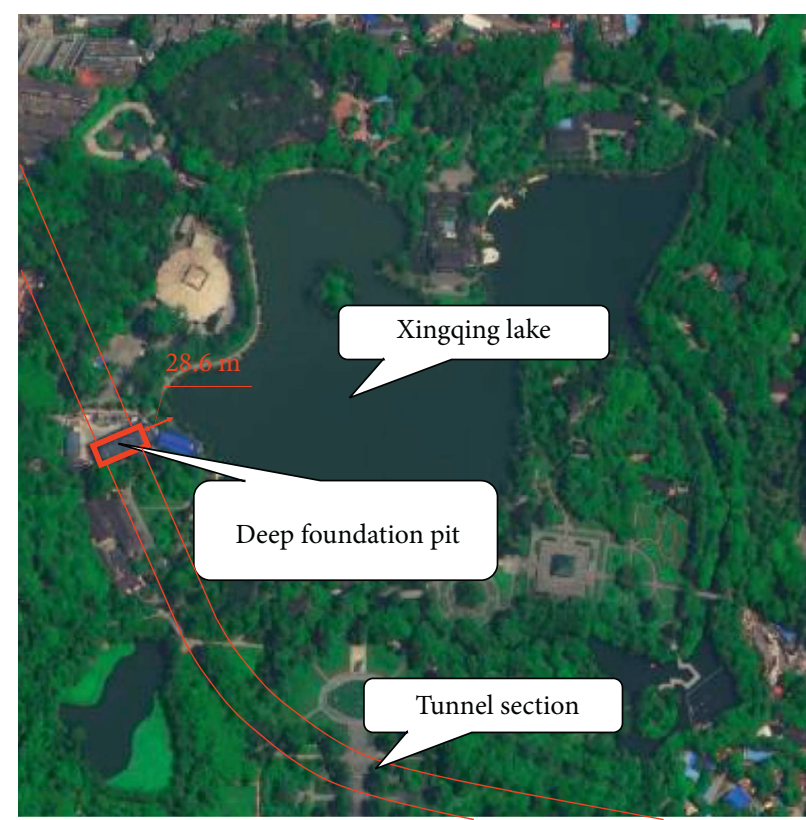

FIgURE 2: The location of the foundation pit.

continuous underground wall, and the supporting system. The layout of the measuring points is shown in Figures 6 and 4 , and the main monitoring items are shown in Table 2.

3.3. Analysis of Working Conditions. The foundation pit monitoring data collection work took 79 days from the erection of the second steel support to the removal of the first steel support. To study the general law of mutual influence among water level, ground settlement, and enclosure structure, the foundation pit was divided into 14 working conditions, as shown in Table 3.

\section{Analysis of Monitoring Results}

4.1. Analysis of Groundwater Level and Surface Subsidence Data. Before this experiment, the foundation pit had been dewatered for 20 days. After the water level in the pit fell below $-31.5 \mathrm{~m}$, the foundation pit began to be excavated. The monitoring data of the longitudinal observation wells GJ3, GJ5, GJ6, and GJ8 of the foundation pit were extracted, and the data from the beginning of the deep foundation pit to when the water level outside the pit stabilized were selected for analysis, which lasted for 64 days. The groundwater-level monitoring curve of the dewatering wells in each pit is shown in Figure 7. It can be seen from the figure that the overall trends of the 4 observation wells were consistent. 36 days ago, due to the continuous precipitation of the foundation pit, the water levels of the 4 observation wells were all decreasing; after 36 days, the water level outside the pit fluctuated due to the occurrence of water gushing; and the water level gradually stabilized after the water gushing problem was solved. The final descending water levels of the observation wells were $-3 \mathrm{~m},-2.5 \mathrm{~m},-4.1 \mathrm{~m}$, and $-3.9 \mathrm{~m}$, respectively. The analysis shows that due to the replenishment of the water source, the water levels of the observation 


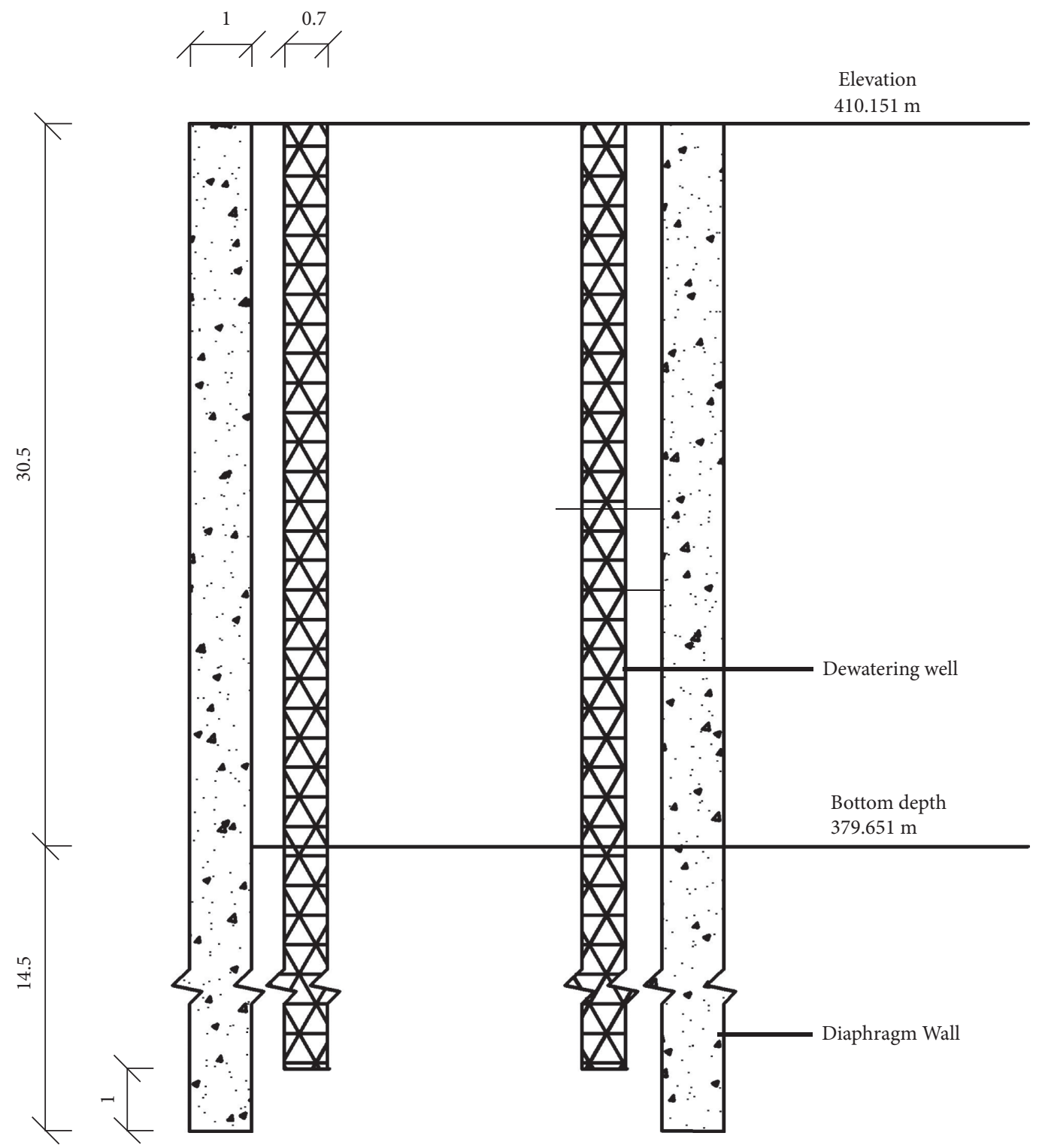

FIGURE 3: Underground diaphragm wall structure design (unit: m).

TABle 1: Physical and mechanical parameters of soil.

\begin{tabular}{lccccc}
\hline Stratum & Dry weight $\left(\mathrm{kN} / \mathrm{m}^{3}\right)$ & Cohesion $(\mathrm{kPa})$ & Internal friction angle $\left({ }^{\circ}\right)$ & Permeability coefficient $\left(\mathrm{m} / \mathrm{d}^{-1}\right)$ & Poisson's ratio \\
\hline Plain fill & - & 10 & 12.0 & - & 5 \\
Saturated soft loess & 14.7 & 15 & 15.0 & 4 & 0.38 \\
Paleosol & 16.4 & 20 & 18.0 & 3 & 0.37 \\
Old loess (soft) & 16.6 & 20 & 18.5 & 3 & 0.33 \\
Silty clay & 16.0 & 30 & 21.0 & 25 & 0.35 \\
Nakasago & - & 0 & 32.0 & & 0.30 \\
\hline
\end{tabular}

wells GJ3 and GJ5 on the right side of the foundation pit were significantly higher than those on the left side of the foundation pit and the water levels of the observation wells GJ6 and GJ8 on the other hand.

A total of 29 ground subsidence monitoring points were set up in this experiment. Data from CJ1-1 to CJ5-6 were examined. Figure 8 shows the settlement time-history curve of the 3 loops around the foundation pit. The positive value represents the uplift and the negative value represents the settlement. Referring to Figure 4, taking the center of the foundation pit as the dividing line, it can be seen from Figure 8 that due to the replenishment of nearby water sources, the ground surface on the left side of the foundation pit is partially uplifted, and the ground surface on the right side is partially subsided. On the 14th day of the monitoring, a water inrush occurred near the CX2 monitoring point, and 


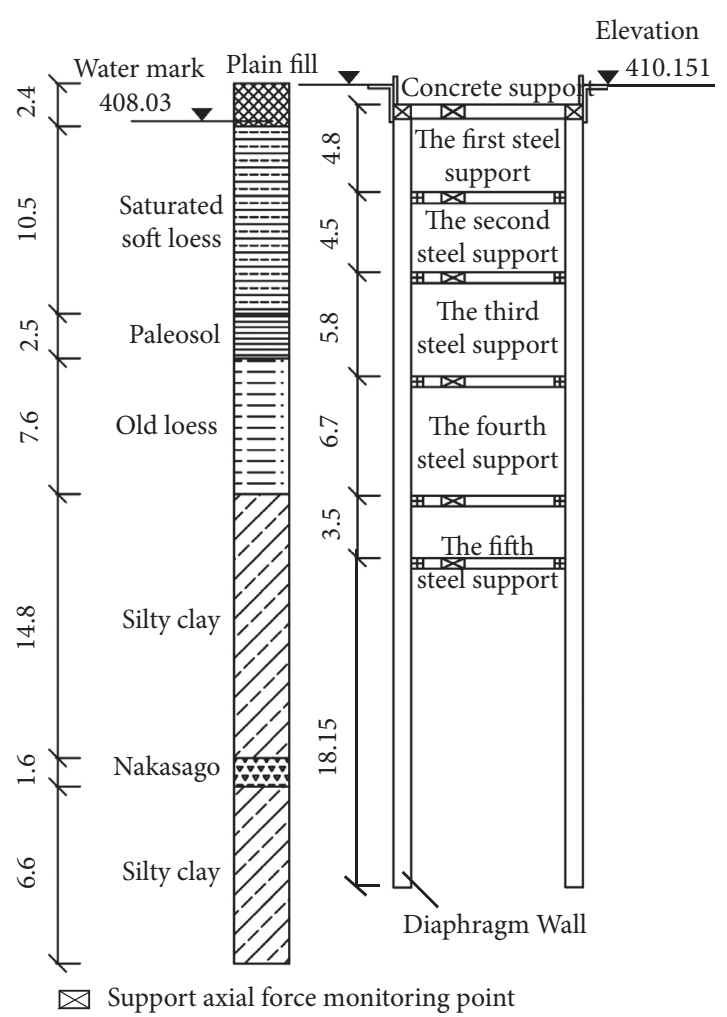

FIgURE 4: Survey point layout (unit: m).

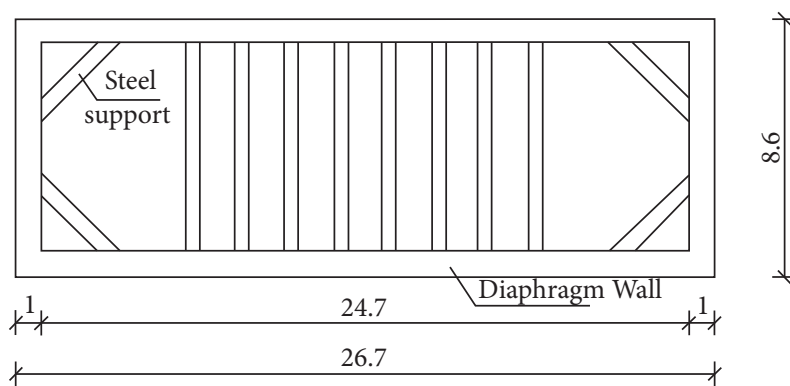

Figure 5: Geological section and cross section of steel support (unit: $\mathrm{m}$ ).

the data fluctuated and began to disperse. After 7 days, the water inrush problem was solved, and the ground subsidence gradually stabilized. Through the comparative analysis of Figure $8(\mathrm{a})-8(\mathrm{c})$, as the distance from the foundation pit increased, the settlement or uplift of the ground outside the pit gradually decreased.

Data were extracted from surface monitoring points CJ3-1, CJ3-2, CJ3-3, CJ3-4, and CJ3-5, and the changes were analyzed in surface settlement from the installation of the second steel support to the end of the negative second floor inverted support construction. As shown in Figure 9, it can be seen that due to the water supply on the right side of the foundation pit, the ground surface on the left side of the foundation pit is partially uplifted, and the ground surface on the right side is partially subsided. At the same time, in condition S6, the data begin to change when water inrush occurs, and then the data are stable.
An analysis was conducted from the installation of the second steel support to the removal of the second and first steel supports, the locations of the largest settlement and the largest uplift of the ground surface, as shown in Figure 10. It can be seen from the figure that the foundation pit construction has the greatest impact on CJ5-5 before the water inrush. However, the surface settlement deformation is small, and the deformation is relatively slow. After the water gushing, the uplift value of CJ4-4 is the largest, and the settlement value of CJ2-5 is the largest. The surface uplift and settlement are both experiencing high acceleration until the water gushing problem is solved.

The aforementioned data analysis shows that the water gushing from the foundation pit significantly impacts the groundwater level and surface settlement. During the construction of the foundation pit, attention should be paid to the changes in the groundwater level and ground settlement to avoid water inrush accidents.

Figure 11 shows the maximum settlement $(\mathrm{Hz})$ ratio of the measured points of the actual measurement target section to the maximum excavation depth $(\mathrm{H})$ of the foundation pit. It can be seen from the figure that the surface settlement increases with the increase in the excavation depth of the foundation pit. The maximum surface uplift distribution range is $0.0023 \% \mathrm{H} \sim 0.0215 \% \mathrm{H}$, with an average value of $0.0111 \% \mathrm{H}$, and the maximum surface subsidence distribution range is $0.0032 \% \mathrm{H} \sim 0.0187 \% \mathrm{H}$, with an average value of $0.0096 \% \mathrm{H}$. The average value is less than the average value of $0.043 \% \mathrm{H}$ calculated by the statistics of the $\mathrm{Xi}^{\prime}$ an loess area [12]. This is due to the reduction of surface settlement caused by the water source replenishment near the foundation pit, which is less than the average value of the Xi'an loess area.

Figure 12 is a histogram of the maximum settlement of each measurement point in the actual measurement target section. Figure 12 shows that among all the measurement points in the actual measurement bid section, the maximum uplift value of the surface outside the pit is $6.57 \mathrm{~mm}$, the average value is $2.432 \mathrm{~mm}$, the maximum settlement value is $5.68 \mathrm{~mm}$, and the average value is $1.286 \mathrm{~mm}$. This is due to the replenishment of the water source causing the surface uplift value to be greater than the settlement value.

Through comparison, it is found that the ground settlement caused by deep foundation pit excavation is very different due to the difference in soil quality. Long and Michael [10] studied Hong Kong and other soft soil areas and Hashash [29] studied that the clay layer foundation pit characteristics are not much different. The maximum surface settlement distribution range is distributed between $0.08 \% \mathrm{H}$ and $0.15 \% \mathrm{H}$; Moormann's [11] statistics show that the surface subsidence range of soft clay areas is from $0.5 \% \mathrm{H}$ to $2 \% \mathrm{H}$; the surface subsidence range of Xi'an and other loess areas studied by Mei et al. [12] ranges from $0.0114 \% \mathrm{H}$ to $0.02 \% \mathrm{H}$. Compared with the above-mentioned soil quality, saturated soft loess has higher compressibility and lower strength. When excavating deep foundation pits in saturated soft loess areas, special attention will be paid to changes in the groundwater level during the design and construction stages. Dewatering causes changes in the groundwater 

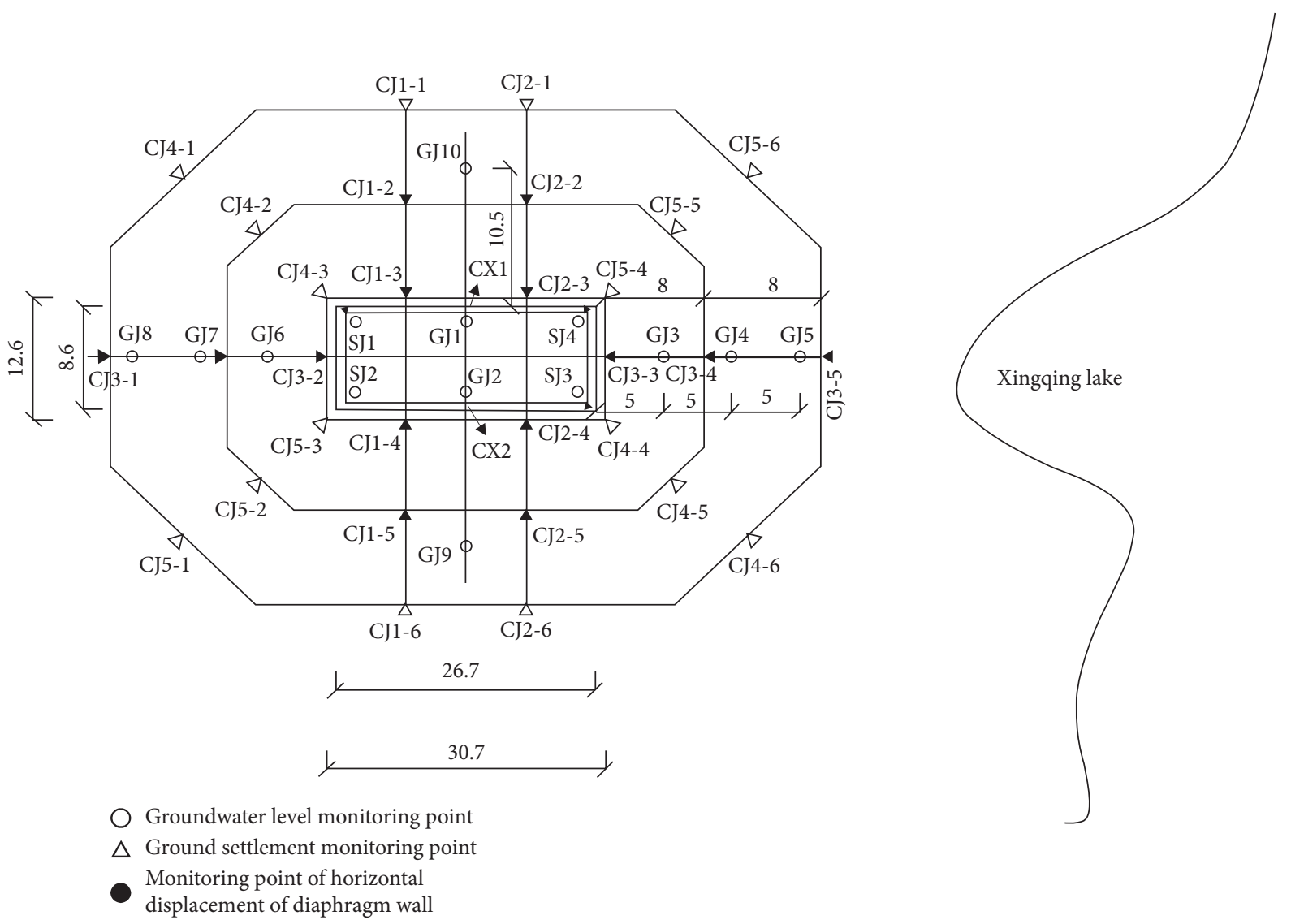

Figure 6: Plan of steel support (unit: m).

TABLE 2: Main items of foundation pit monitoring.

\begin{tabular}{|c|c|c|c|c|c|}
\hline $\begin{array}{l}\text { Serial } \\
\text { number }\end{array}$ & Monitoring items & $\begin{array}{l}\text { Monitoring } \\
\text { instrument }\end{array}$ & Measuring point layout & $\begin{array}{c}\text { Measurement } \\
\text { accuracy }\end{array}$ & Allowance \\
\hline 1 & $\begin{array}{l}\text { Surface settlement } \\
\text { around the pit }\end{array}$ & Level & $\begin{array}{l}\text { Arrange } 2 \text { rings along the circumference of } \\
\text { the pit, the first ring is } 2.0 \mathrm{~m} \text { away from the } \\
\text { periphery of the foundation pit, the second } \\
\text { ring is } 8 \mathrm{~m} \text { away from the periphery of the } \\
\text { first ring, and the distance between the } \\
\text { measuring points of each ring is } 10-20 \mathrm{~m}\end{array}$ & $1.0 \mathrm{~mm}$ & $\begin{array}{c}0.3 \% \mathrm{H} \text { or } \\
\leq 30 \mathrm{~mm} \text {, } \\
\text { whichever is } \\
\text { smaller }\end{array}$ \\
\hline 2 & $\begin{array}{c}\text { Horizontal } \\
\text { displacement of } \\
\text { diaphragm wall }\end{array}$ & $\begin{array}{c}\text { Theodolite Total } \\
\text { station }\end{array}$ & $\begin{array}{l}\text { Layout along with the middle and outside } \\
\text { corners of the periphery of the foundation } \\
\text { pit, with a spacing of no more than } 20 \mathrm{~m} \text {, and } \\
\text { no less than } 3 \text { underground continuous walls } \\
\text { on each side }\end{array}$ & $1.0 \mathrm{~mm}$ & $\begin{array}{c}0.2 \% \mathrm{H} \text { or } \\
\leq 30 \mathrm{~mm} \text {, } \\
\text { whichever is } \\
\text { smaller }\end{array}$ \\
\hline 3 & Support axial force & $\begin{array}{l}\text { Axial force gauge } \\
\text { Strain gauge }\end{array}$ & $\begin{array}{l}\text { The deformation of the diaphragm wall is set } \\
\text { at the same monitoring section, and the } \\
\text { vertical supports at the same section position } \\
\text { are set at measuring points }\end{array}$ & $0.15 \%$ F.s & $0.8 \mathrm{f}$ \\
\hline 4 & Groundwater level & $\begin{array}{l}\text { Water-level pipe } \\
\text { Water-level meter }\end{array}$ & $\begin{array}{l}\text { The midpoint of the long and short sides of } \\
\text { the foundation pit, and the distance between } \\
20 \text { and } 50 \mathrm{~m} \text { when the foundation pit is large, } \\
\text { needs to be combined with the precipitation } \\
\text { plan }\end{array}$ & $5.0 \mathrm{~mm}$ & \\
\hline
\end{tabular}

outside the pit, which will cause the pore water pressure in the soil to drop. According to the principle of effective stress, the decrease of pore water pressure in the soil layer will increase the effective stress, leading to the compression of the soil layer and the decrease of porosity. However, the ground subsidence caused by the excavation of the deep 
TABLE 3: Main analysis conditions of foundation pit.

\begin{tabular}{lcc}
\hline Working condition & Content & Duration/day \\
\hline S1 & Install the second steel support & 1 \\
S2 & Excavate to $17 \mathrm{~m}$, install the third steel support & 3 \\
S3 & Excavate to $23 \mathrm{~m}$, install the $4^{\text {th }}$ steel support & 4 \\
S4 & Excavate to $27 \mathrm{~m}$, install the $5^{\text {th }}$ steel support & Excavation to $30.45 \mathrm{~m}$ \\
S5 & Start gushing water-gushing solution \\
S6 & Slab pouring \\
S7 & Demolition of the 5 th steel support \\
S8 & Negative second floor inverted support construction \\
S9 & 4 th steel support removal \\
S10 & Construction of sidewall and floor frame beam on the second floor \\
S11 & Removal of the 3rd steel support \\
S12 & Construction of frame beams on the sidewall of the negative first floor \\
S13 & Demolition of the second and first steel supports \\
S14 & & 2 \\
\hline
\end{tabular}

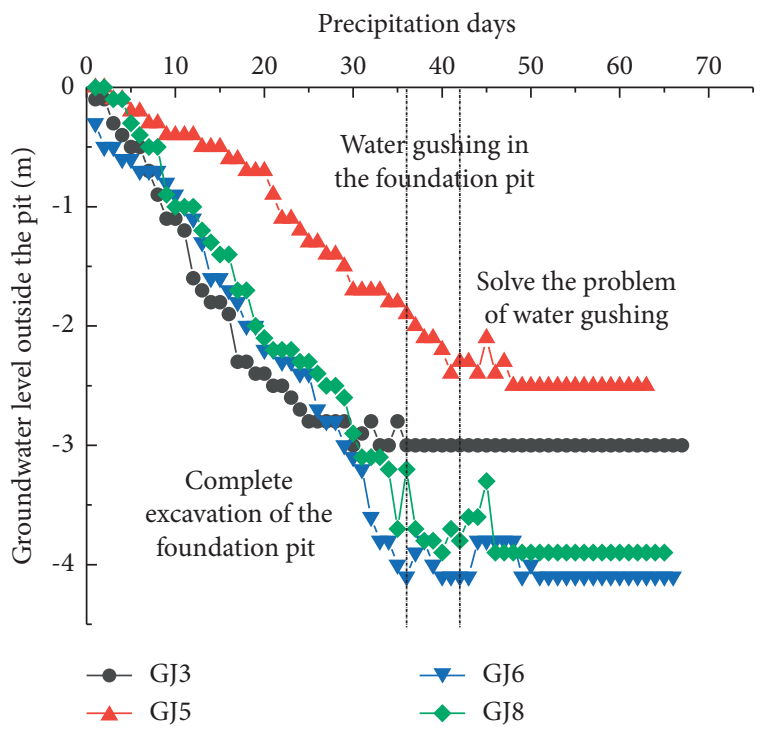

FIgURE 7: Water-level change curve outside the pit.

foundation pits studied in this paper is smaller than that in other areas. This is due to the special situation of water sources near the test area. Recharge was carried out during the precipitation process, which weakened the impact of precipitation on soil compression.

It can be seen that due to the nearby water supply, the surface settlement caused by deep foundation pit excavation in the saturated soft loess area is smaller than that in other areas. However, it should be noted that the saturated soft loess has greater compressibility and low strength. During the excavation of deep foundation pits, once the water level outside the pit drops too much, the consequences are often serious. Special attention and control of ground settlement should be given during design and construction.

Figure 13 shows the distribution of the maximum surface settlement deformation of the monitored section and the ratio of the distance from the edge of the foundation pit to the excavation depth of the foundation pit during the excavation of the foundation pit. It can be seen that the settlement points caused by the excavation of the foundation pit all fall within the area I summarized by Peck [30]; the average distance between the maximum vertical deformation position of the ground surface and the edge of the foundation pit is $0.341 \mathrm{H}$, which is less than the average value of the Xi'an loess area; and the statistical average is $0.521 \mathrm{H}$ [12]. This is because the water level outside the pit in the test area is higher than the average water level in the Xi'an loess area, and the pore pressure of the soil layer is large, resulting in less ground settlement. Therefore, the average distance between the maximum vertical deformation position of the ground surface and the edge of the foundation pit is less than the statistics of the Xi'an loess area. The average value was obtained.

Due to the small excavation area of the foundation pit and the presence of nearby water sources, the groundwater was recharged during the excavation of the foundation pit. So the surface settlement outside the pit is small, but it will cause surface swelling outside the pit. Therefore, during this process, we need to pay attention to the surface subsidence and the surface uplift.

4.2. Data Analysis of Horizontal Displacement of the Diaphragm Wall. Using the CX1 monitoring point as an example to analyze the horizontal displacement of the ground connecting wall, Figure 10 shows the horizontal displacement curve of the diaphragm wall under different working conditions. From Figure 14(a) and 14(b), it can be seen that the horizontal displacement curve of the diaphragm wall under different working conditions has the exact change. Due to the installation and removal of the steel support, the underground diaphragm wall and the middle change are large. Due to the upper concrete and the lower soil support, the deformation at the lower ends of the continuous underground wall is smaller. It can be seen from the figure that as the excavation depth of the foundation pit increases, the deformation of the underground continuous wall is "serrated," which is different from the general "bow" [14]. This is because the preaxial force of the steel support is too large, resulting in the continuous underground wall not being able to bear the force together with the steel support. 


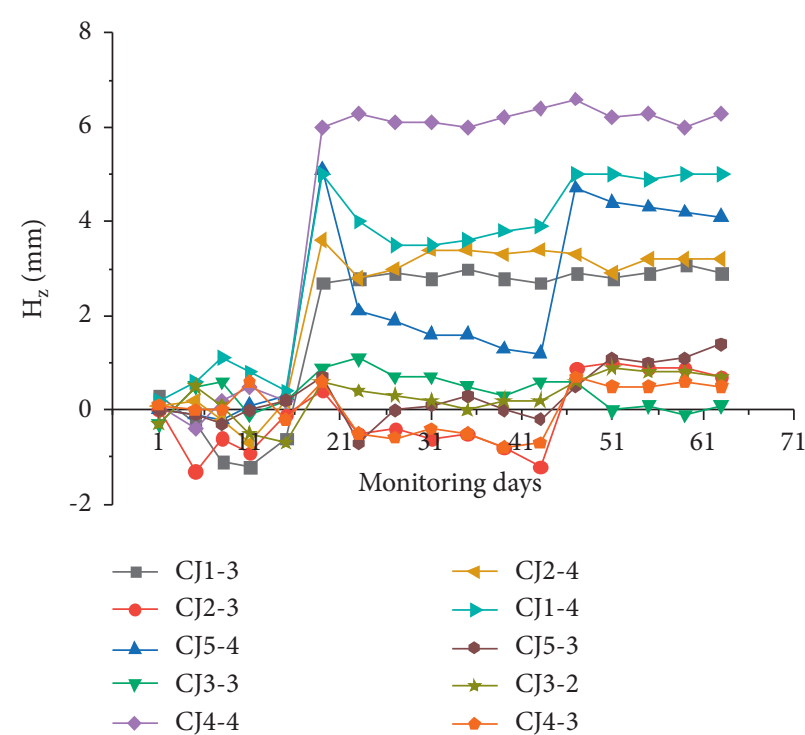

(a)

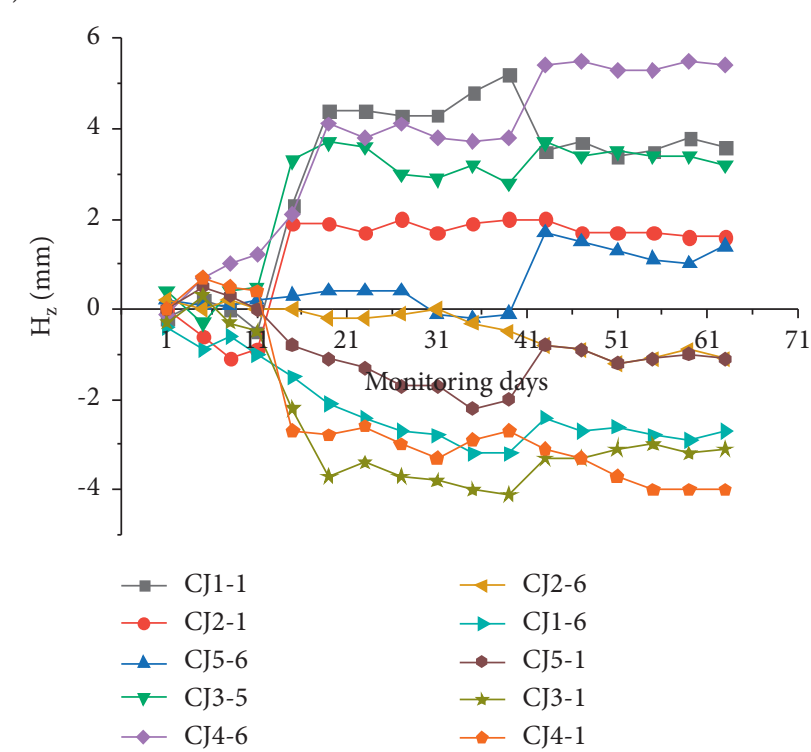

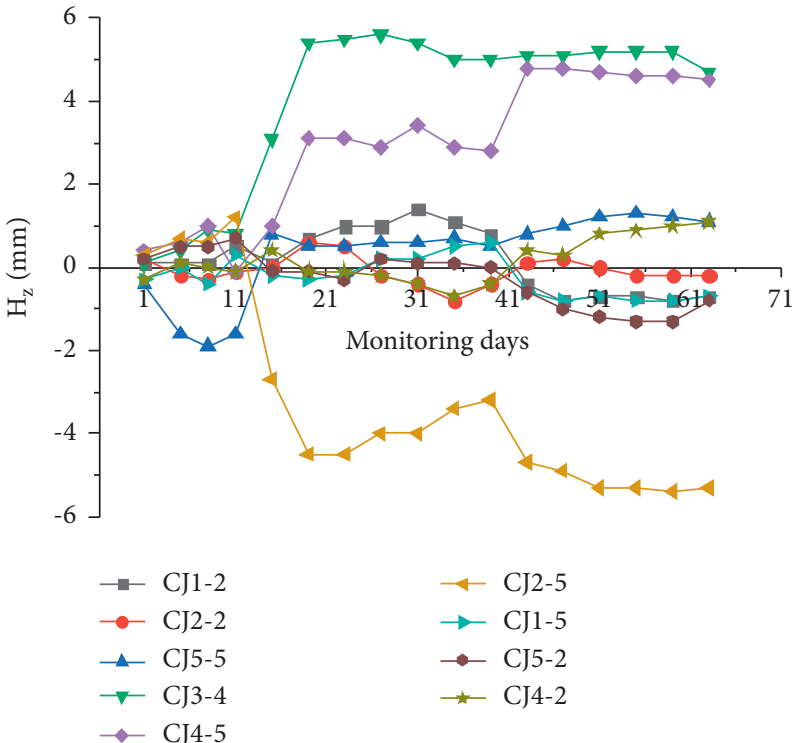

(b)

(c)

Figure 8: Change curve of surface settlement. (a) First ring. (b) 2nd ring. (c) 3rd ring.

Figure 14(c) shows the relative horizontal displacement curve of the underground diaphragm wall between different working conditions. It can be seen from Figure 14 that the relative horizontal displacement between working conditions is gradually decreasing. It shows that working condition S3 has a greater impact on the diaphragm wall. This is because when the fourth steel support is installed, the preaxial force of the steel support is too large, and the supporting structure does not effectively share the same effect. During the excavation of the foundation pit, the ground connecting wall bears greater lateral pressure of the soil, resulting in the deformation of the ground connecting wall into the pit. Working conditions S9 and S10 have a greater impact on the continuous underground wall due to the negative two of S9. The construction of the layered inverted sidewall makes the continuous underground wall completely expand outward compared to the previous working condition. The above data analysis shows that the water gushing from the foundation pit has a huge impact on the surface settlement.

Therefore, the preaxial force of the steel support should be reasonable so that the supporting structure can effectively work together to avoid excessive deformation of the ground connecting wall. Speeding up the construction of inverted sidewalls, floor frame beams, and sidewall frame beams can alleviate the impact of steel support removal on the continuous underground wall.

Figure 15 shows the cumulative curve of the displacement of the maximum and minimum deformation points of the diaphragm wall over time. It can be seen that in the 


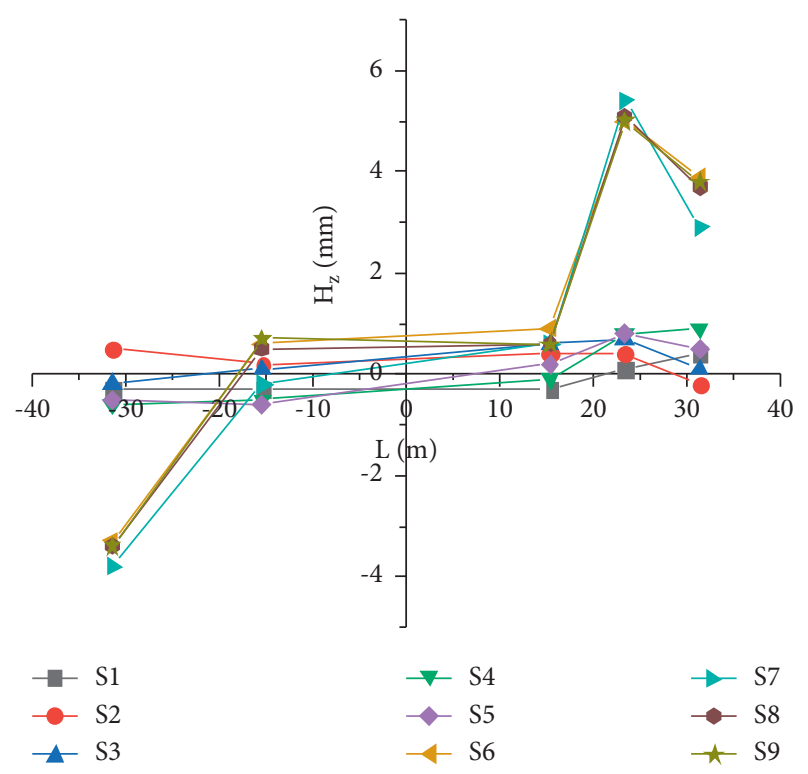

Figure 9: Changes in surface settlement under different working conditions.

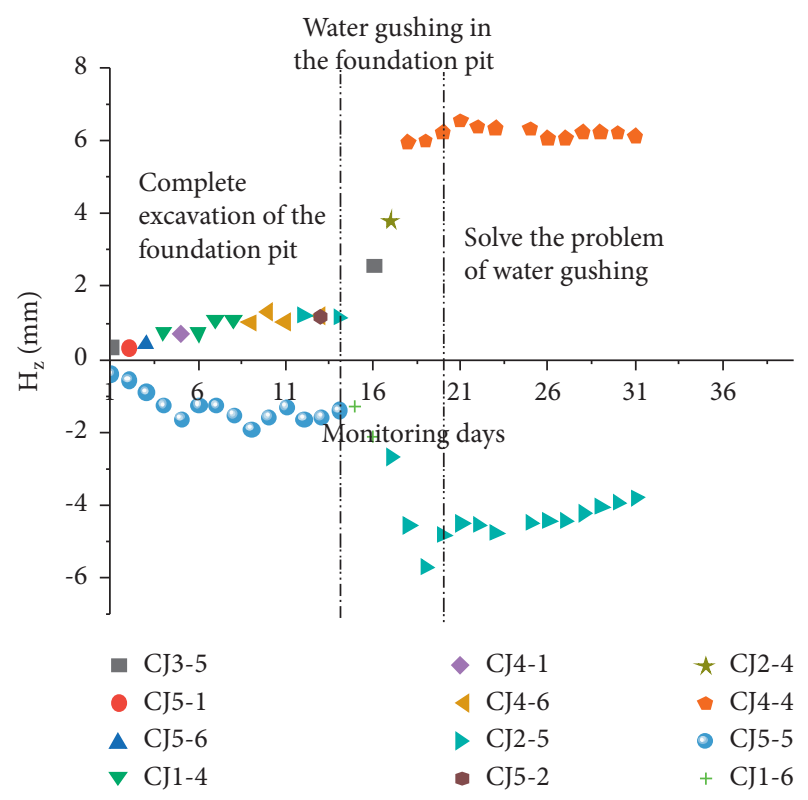

FIGURE 10: Changes in measurement points of the largest uplift and subsidence on the surface.

S4-S6 stage, the horizontal displacement speed of the ground connecting wall is called S1-S3 and is relatively slow; in the S7-S8 stage, due to the removal of the fifth steel support, the maximum and minimum horizontal deformations of the ground connecting wall are reduced. The underground wall deforms into the pit; the S9-S14 stage: after the negative two-story inverted bracing is completed, the continuous underground wall gradually shifts outward, and with the construction of the inverted brace, the floor frame beam, and the sidewall frame beam, the underground is continuous. The wall is restrained by its rigidity, effectively controlling the development of horizontal deformation of

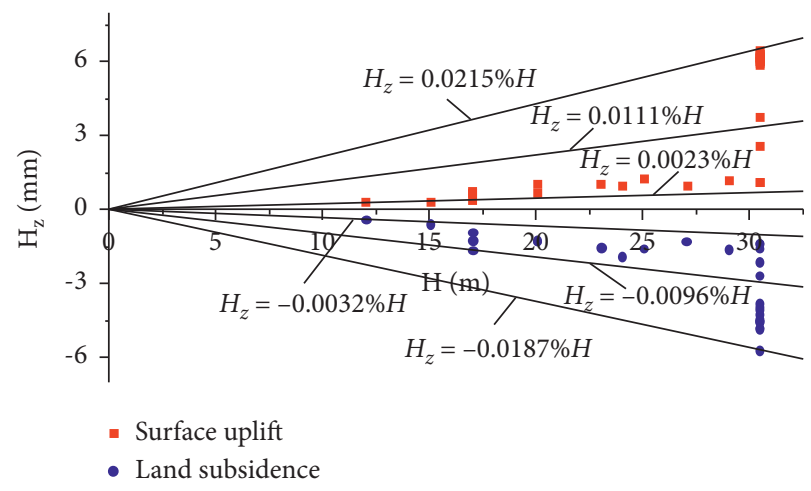

FIGURE 11: The relationship between the maximum surface uplift, settlement, and excavation depth.

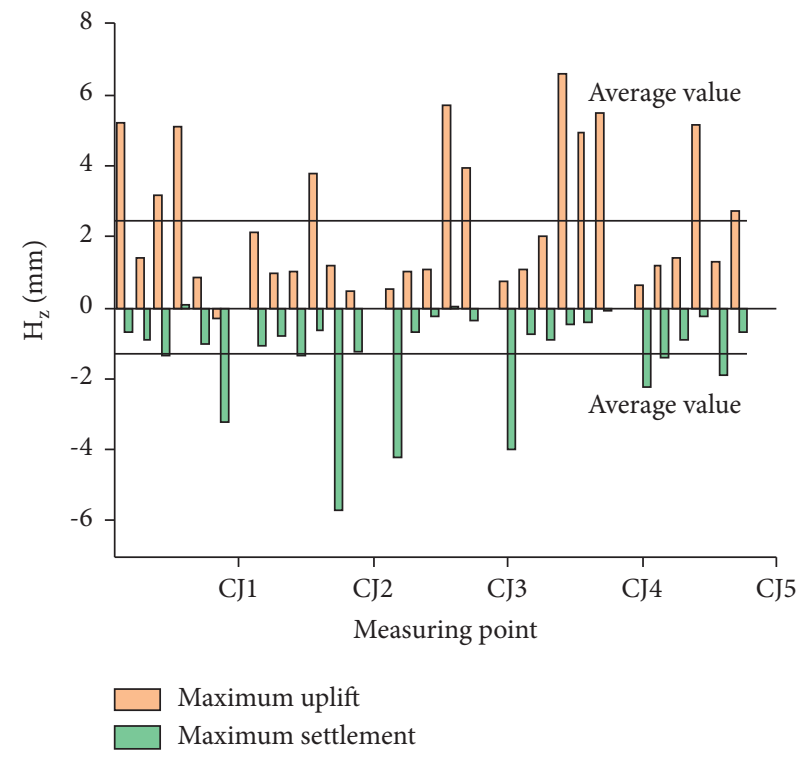

FIGURE 12: Histogram of the maximum uplift and settlement values outside the pit.

the continuous underground wall. Figure 16 shows that the maximum horizontal displacement of the external wall expansion is mainly distributed at $5 \mathrm{~m}$ and $11 \mathrm{~m}$, which is a saturated soft loess area. The saturated soft loess has the characteristics of a large pore structure and high compressibility, so the wall is easy to expand. The maximum horizontal displacement of internal shrinkage is mainly distributed at $17.5 \mathrm{~m}$ and $22.5 \mathrm{~m}$, which is the old loess area. The old loess has the properties of a compact structure, high strength, and local flow plastic state, so the wall is easy to shrink. Therefore, it is believed that the horizontal displacement of the wall may be related to the distribution of the soil layer. Given the different properties of various soil types, the ground connecting wall is subjected to different lateral pressures of the soil. Therefore, the pit bottom floor, the inverted support, and the floor slab should be accelerated during the construction process. The construction speed of the frame beams and the sidewall frame beams restrains the deformation of the continuous underground wall. Meanwhile, the deformation monitoring of the continuous 


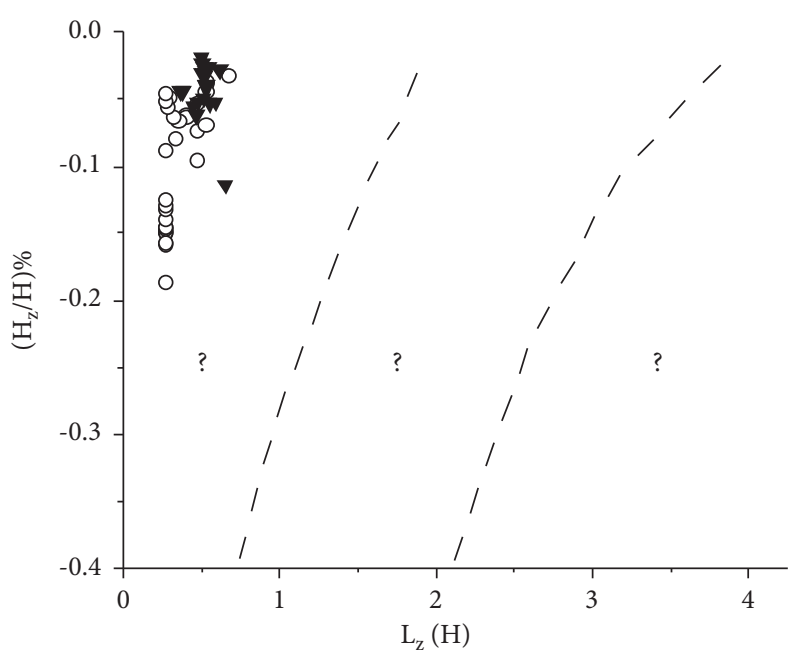

Area I: sandy soil, hard clay, soft clay;

Area II: soft clay and very weak clay;

Area III: soft clay with thick depth and extremely soft clay

O This pit

$\boldsymbol{\nabla}$ Statistics of Xian deep foundation pit

Figure 13: Ground settlement caused by excavation of foundation pit.

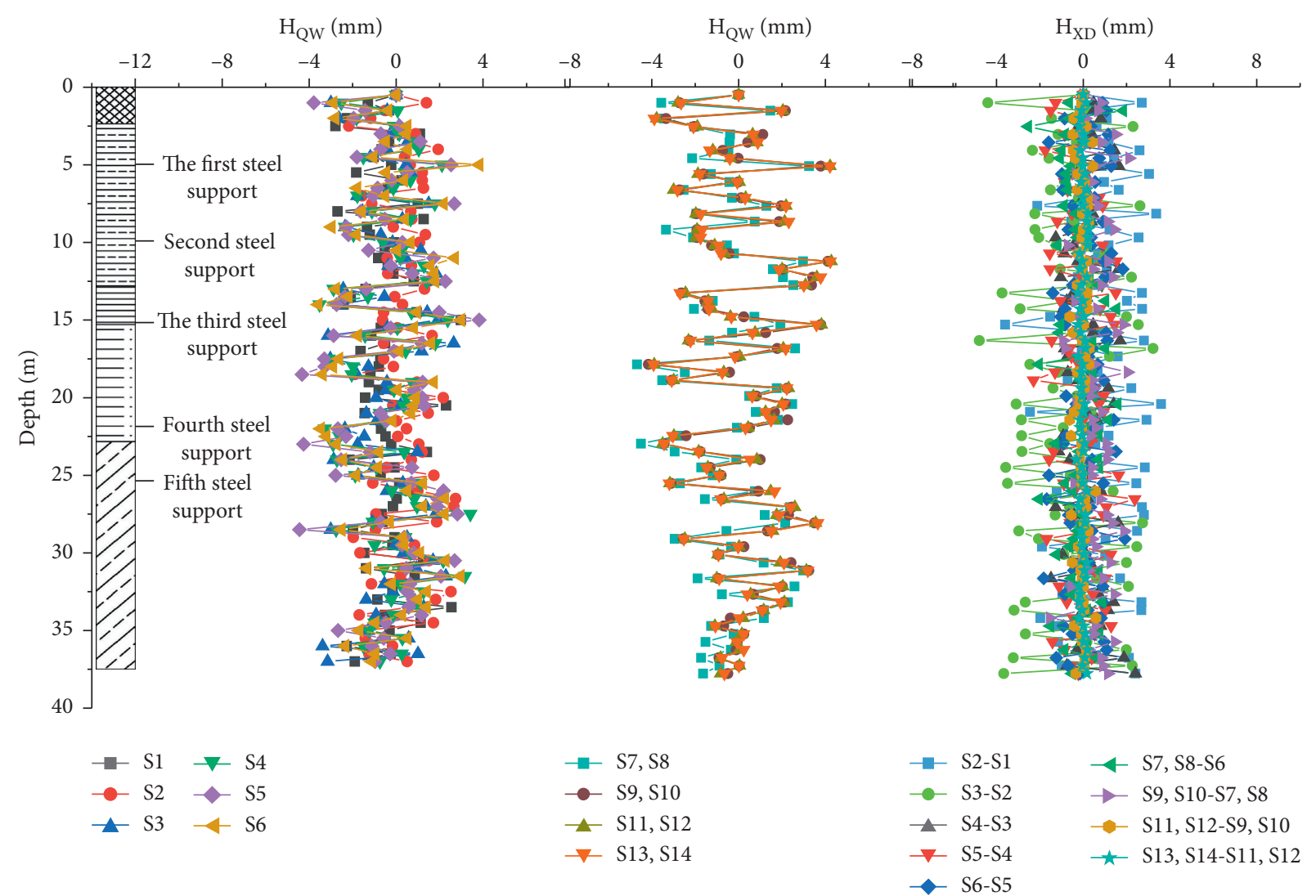

(a)

(b)

(c)

FIGURE 14: Horizontal deformation of ground connecting wall. 


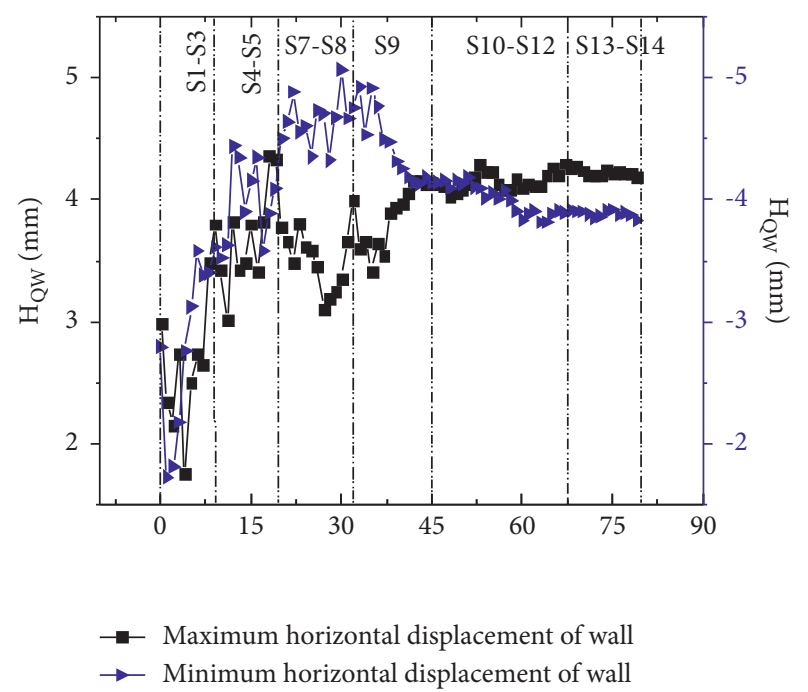

Figure 15: The cumulative curve of the displacement of the maximum and minimum deformation point of the ground connecting wall with time.

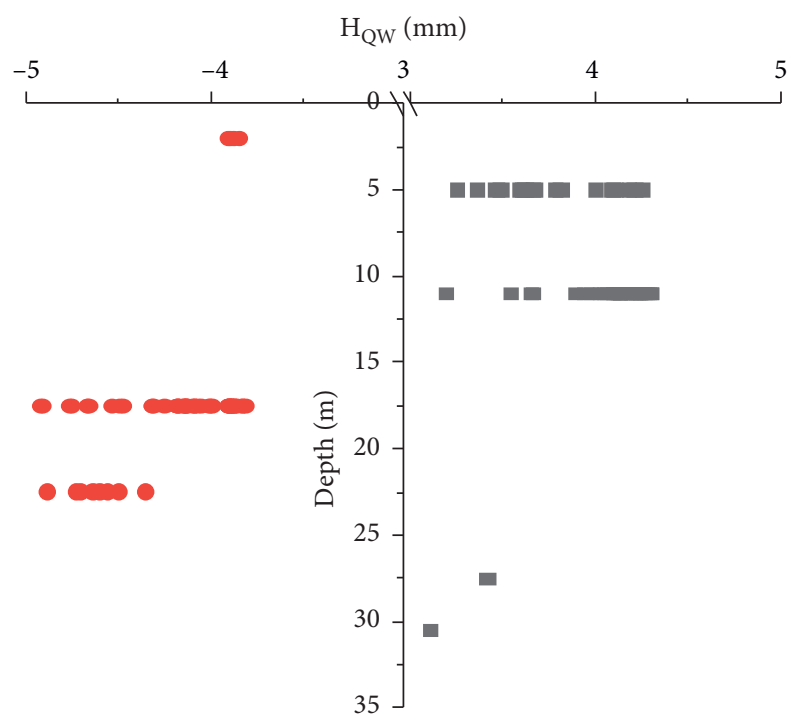

- Maximum horizontal displacement of the wall

- Minimum horizontal displacement of the wall

FIGURE 16: Distribution of the maximum and minimum horizontal displacement of the ground connecting wall.

underground wall should continue until the deformation is stable to ensure the safety of the construction.

Figure 17 shows the ratio of the horizontal displacement of the diaphragm wall $\left(H_{Q W}\right)$ to the maximum excavation depth $(\mathrm{H})$ of the foundation pit. It can be seen from the figure that the wall deformation increases with the increase of the excavation depth of the foundation pit. The maximum horizontal displacement distribution range of the ground connecting wall outside the pit is $0.0102 \% \mathrm{H} \sim 0.0248 \% \mathrm{H}$, with an average value of $0.0133 \% \mathrm{H}$. The maximum horizontal displacement distribution range along the pit is $0.0107 \% \mathrm{H} \sim 0.0233 \% \mathrm{H}$, with an average value of $0.0141 \% \mathrm{H}$.

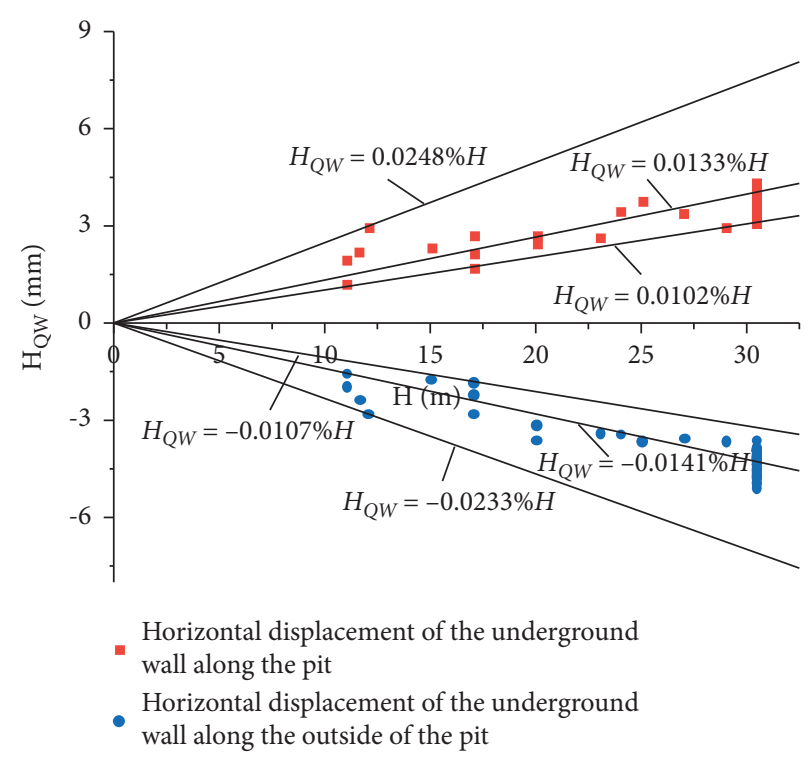

FIgURE 17: The relationship between the horizontal displacement of the underground wall and the excavation depth.

The distribution range is less than the distribution range of the Xi'an loess area, which is $0.0046 \% \mathrm{H} 0.0994 \%$ [12], and the average value is less than the average value of $0.0366 \% \mathrm{H}$ [12]. This is because the preadded axial force is too large when laying steel supports, which fails the effective interaction of the enclosure structure. Therefore, the average value of the ratio of the horizontal displacement of the underground diaphragm wall $\left(H_{Q W}\right)$ to the maximum excavation depth $(\mathrm{H})$ of the foundation pit is smaller than Xi'an. The statistics of the loess area obtain the average value.

Therefore, the preadded axial force of the steel support should be reasonable so that the supporting structure can work together to avoid an excessive increase in the axial force of some steel supports.

4.3. The Relationship between the Vertical Deformation of the Ground Surface and the Lateral Deformation of the Diaphragm Wall. During the dewatering and excavation of foundation pits, the earth pressure is unbalanced and the enclosure structure is deformed, while the ground surface behind the envelope structure is also deformed, which causes the surface deformation to be closely related to the lateral deformation of the ground connecting wall. Figure 18 shows the relationship between the maximum surface settlement and the maximum horizontal deformation of the ground connecting wall. The figure shows that the surface settlement increases with the increase of the ground connecting wall deformation, and the main distribution range of the maximum surface settlement is $0.24, H_{Q W \max } \sim 1.37 H_{Q W \max }$. Since the foundation pit studied in this paper is close to the water source and the surface settlement is small, the distribution range of the maximum surface settlement value is smaller than the lower limit of the range calculated by the Xi'an loess area, $0.65 H_{Q W \max }[12]$.

Through comparison, it is found that the relationship between the vertical deformation of the ground surface and 


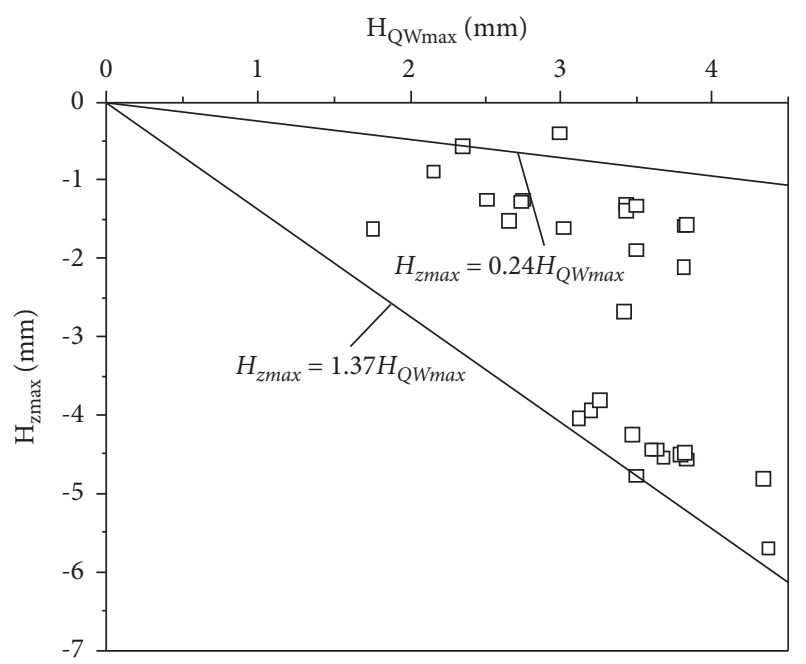

FIgURE 18: The relationship between the maximum vertical deformation of the ground surface and the maximum lateral deformation of the ground connecting wall.

the lateral deformation of the diaphragm wall is very different due to the difference in soil quality. Because of this relationship, Clough [9] believes that $H=(0.5 \sim 1.5) H_{Q W \max }$ exists in the sand, hard clay, and soft clay areas; Mana [31] believes that $H=(0.5 \sim 1.0) H_{Q W \max }$ exists in clay areas; according to $\mathrm{Ou}$ [32], there is $H=(0.5 \sim 0.7) H_{\mathrm{QWmax}}$ in the Taipei area; Moormann [11] has $H=(0.5 \sim 2.0) H_{Q W \max }$ in the soft clay area; Wang et al. [33] analyzed the depth of the soft soil area in Shanghai and, for excavation of foundation pits, considered $H=(0.4 \sim 2.0) H_{Q W \max }$; Mei et al. [12] calculated the loess area in Xi'an and considered $H=(0.65 \sim 2.0)$ $H_{\mathrm{QWmax}}$; and Xiao et al. [34] analyzed 92 soft soil foundation pits in China, It is considered that there is $H=(0.2 \sim 2.5)$ $H_{Q W \max }$. In the saturated soft loess area studied in this paper, the ratio of the surface settlement to the lateral deformation of the diaphragm wall is within the range of Xiao's statistics, but it is smaller than other areas. This is due to the small settlement value of the soil caused by the replenishment of nearby water sources. It can be seen that the deformation of the foundation pit is not only related to soil quality, design, and construction factors, but the special environment of the area may also be an important factor, such as the water source near the test area.

4.4. Steel Support Axial Force Data Analysis. The fourth monitoring section has been used as the main section to analyze the variation of the axial force of each steel support with the excavation depth of the foundation pit, as shown in Figure 19. GZC1-4 indicates the axial force monitoring point of the first support section of the fourth section. Overall, the axial force of the first support is the smallest and gradually stabilized, and the axial force of the second, third, fourth, and fifth steel supports increases with the increase in the excavation depth. This is due to the increased pressure on the front side due to excavating the deep foundation pit. When the soil is unloaded, the passive earth pressure is reduced, and the continuous underground wall along with the pit is

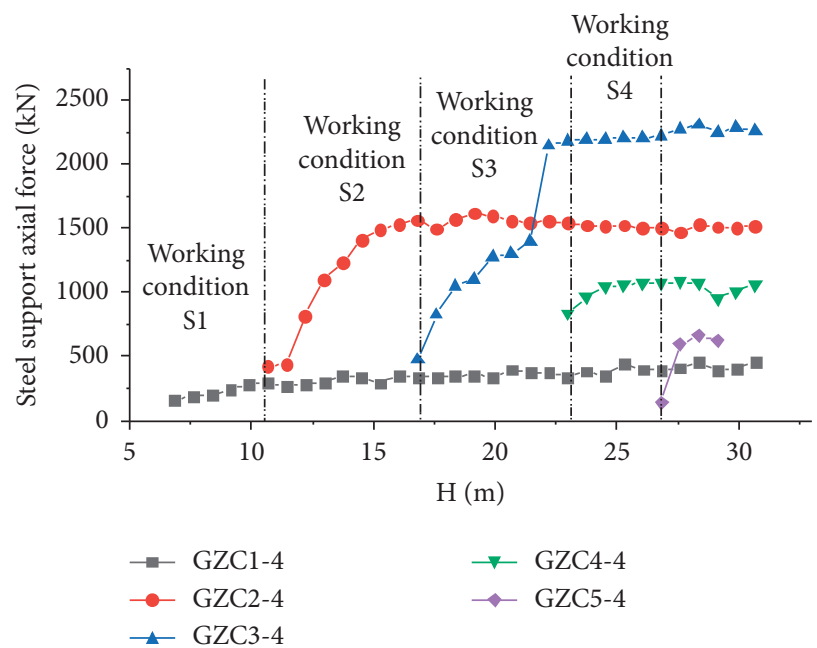

FIgURE 19: The change of steel support axial force with excavation depth.

deformed, causing the axial force of the steel support to increase.

It can be seen from the figure that the emergence of axial force has the characteristics of "immediateness," and it is generated synchronously with the excavation. At the same time, as the excavation stage S1 progresses, the axial force at GZC1-4 slowly increases, but in stages S3 and S4, as the depth of the excavation further increases, the axial force at GZC2-4 and GZC3-4 appears to be decreasing. The significant increase is due to the "depth effect" of the excavation.

Figure 20 shows the change curve of the measured axial force of the steel support over time. It can be seen from the figure that the steel support can withstand a large axial force in a short time after installation and remains relatively stable. The supporting axial force of the measuring points of the first and eighth cross sections is slightly smaller than that of the fourth cross section. The axial force of the second steel support still increased significantly after installing the third steel support. It indicates that the second steel support shared part of the earth pressure that the third steel support should bear, resulting in the second steel support. The supporting shaft force exceeds its standard value. The axial force of the third steel support tends to be stable after the fourth support is installed. This is because the fourth support shares the lateral pressure of the third steel support. It can be seen from the figure (b) that when the $5^{\text {th }}$ steel support starts to work, the axial force of the $4^{\text {th }}$ support increases faster. This is because the $5^{\text {th }}$ support does not share the pressure of the $4^{\text {th }}$ support. The continued excavation of the pit caused the 4th support to bear greater lateral pressure of the soil, causing the axial force of the $4^{\text {th }}$ support to exceed its standard value. This is because the preadded axial force of the steel support is too large, and the supporting structure does not work together effectively.

Therefore, the preadded axial force of the steel support should be reasonable so that the steel support, the steel purlin, and the ground connecting wall are in contact with each other without any joint force. In the early stages of 


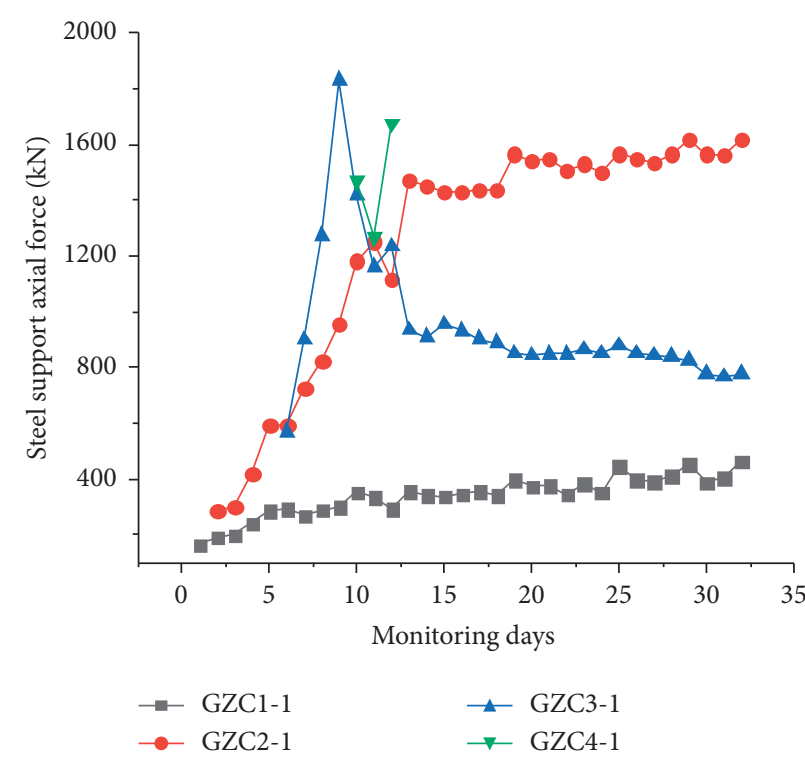

(a)

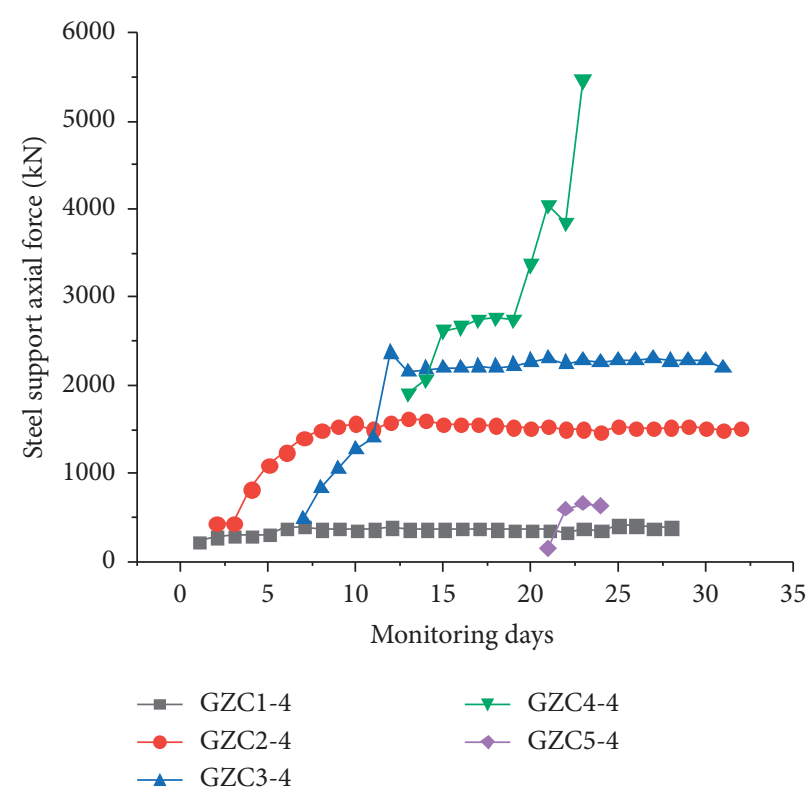

(b)

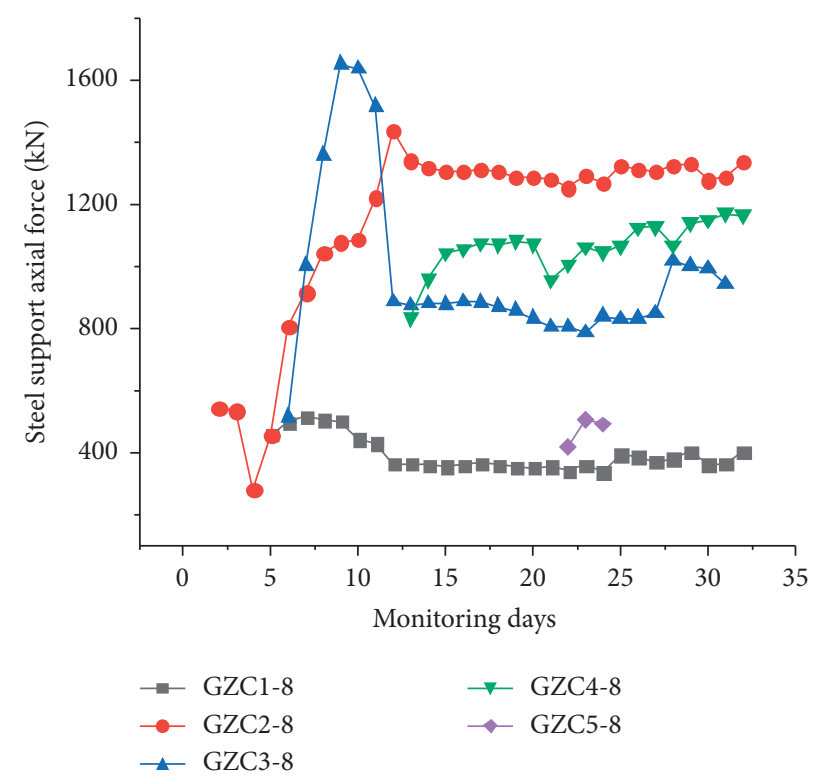

(c)

Figure 20: Axial force change curve of steel support. (a) Change of axial force of steel support at No. 1 section measuring point. (b) Axial force change of steel support at No. 4 section measurement point. (c) Change of axial force of steel support at No. 8 section measuring point.

excavation, it is necessary to speed up the deployment of the steel support and increase the monitoring frequency to prevent the smaller number of tracks from increasing the value of the rest of the supporting axis.

4.5. The Relationship between the Horizontal Deformation of the Diaphragm Wall and the Axial Force of the Steel Support. During the excavation process of the foundation pit, the horizontal displacement of the ground-connecting wall is closely related to the axial force of the steel support. The axial force value of GZC2-4 and the horizontal displacement value of the wall corresponding to the depth are analyzed. As shown in Figure 21, the wall deformation along the pit is set as a negative value. It can be clearly seen from the figure that the axial force of the steel support decreases with the decrease of the horizontal displacement of the ground connecting wall, and shows a certain correlation $\left(R^{2}=0.76\right)$, and the fitting curve generally shows a downward trend. This is because when the earth pressure outside the pit is too large and the wall deforms into the pit, the steel support needs to bear too much earth pressure and the axial force is large. As the wall gradually deforms along the outside of the pit, the steel support does not need to bear it. With a high earth pressure, the axial force gradually decreases. 


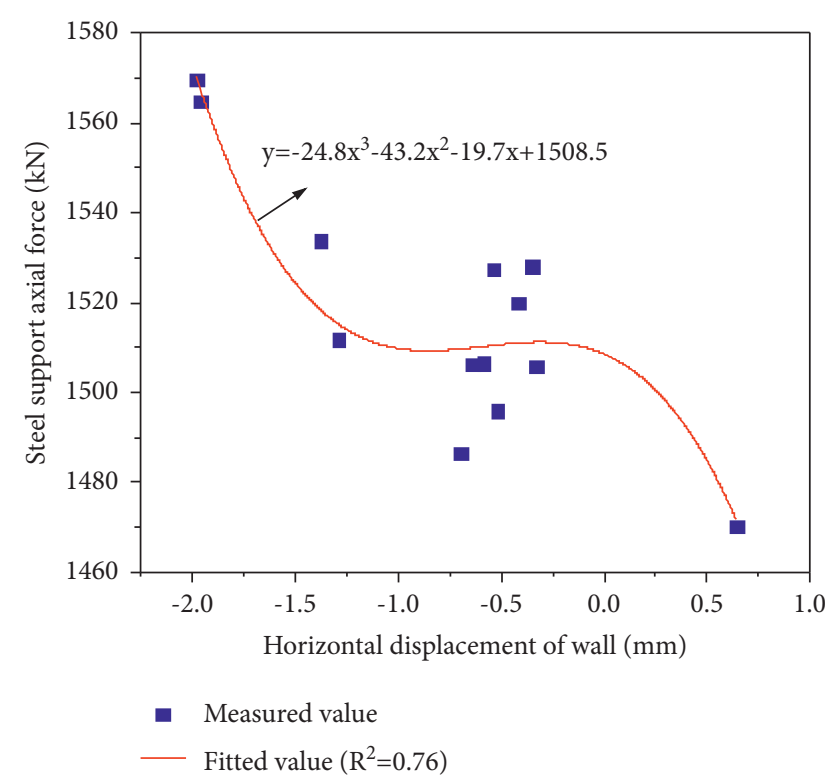

FIGURE 21: The relationship between wall displacement and steel support axial force.

Therefore, during the construction process, it is necessary to speed up the deployment of steel supports, share the axial force of other steel supports, and avoid excessive deformation of the continuous underground wall.

\section{Discussion}

This paper systematically analyzes the changes in the groundwater level, ground settlement, horizontal displacement of the diaphragm wall, and the axial force of the steel support during the excavation of deep foundation pits. At the same time, it analyzes the changes in the ground surface settlement, the horizontal deformation of the diaphragm wall, and the excavation depth. The relationships between the surface settlement and the horizontal deformation of the diaphragm wall and the axial force of the steel support provide a reference for the construction plan for the deep foundation pit excavation in the saturated soft loess area. However, due to the particularity of the location of the deep foundation pit and the construction and other factors studied in this paper, it does not apply to all the deformation modes of the deep foundation pit in the saturated soft loess area.

\section{Conclusions}

Based on a field test of a high-water level deep foundation pit in saturated soft loess, through real-time monitoring and data analysis, the conclusions are as follows:

(1) The average value of the maximum surface uplift outside the pit is $0.0111 \% \mathrm{H}$, and the average value of the maximum surface subsidence is $0.0096 \% \mathrm{H}$ and the average value of the distance between the maximum vertical deformation position of the surface and the edge of the foundation pit is
$0.341 \mathrm{H}$, both of which are smaller than the average value obtained by statistics of Xi' an loess area. The main distribution range of the maximum surface subsidence is $0.24 H_{Q W \max } \sim 1.37 H_{Q W \max }$, which is smaller than the statistical scope of Xi'an loess area. Therefore, in the design and construction stages, the impact of water sources needs to be considered.

(2) The average value of the maximum horizontal displacement along the ground wall outside the pit is $0.0133 \% \mathrm{H}$, and the average value of the maximum along the pit is $0.0141 \% \mathrm{H}$, both of which are smaller than the average value obtained by statistics of Xi' an loess area. Therefore, during the construction process, the steel supports of the axial force should be reasonable to make the supporting structure effectively work together; speed up the construction speed of the bottom slab, the inverted brace, the floor frame beam, and the sidewall frame beam to restrain the deformation of the continuous underground wall.

(3) The supporting axial force sometimes tends to increase and decrease. Meanwhile, the steel supporting axial force declines with the decrease of the ground connecting wall deformation. Therefore, the preadded axial force of the steel support should be reasonable to make the internal support uniformly stressed to avoid local instability. In the early stage of excavation, it is necessary to speed up the deployment of the steel support and increase the monitoring frequency.

\section{Nomenclature}

L: Distance between the measuring point and the center of the foundation pit $(\mathrm{m})$

$L_{\mathrm{z}}: \quad$ The distance between the maximum vertical deformation point of the surface and the edge of the pit $(\mathrm{m})$

$\mathrm{H}: \quad$ Excavation depth $(\mathrm{m})$

$H_{z}: \quad$ Surface subsidence $(\mathrm{m})$

$H_{z \text { max }}: \quad$ Maximum surface settlement $(\mathrm{mm})$

$H_{\mathrm{QW}}$ : Cumulative horizontal displacement of diaphragm wall $(\mathrm{mm})$

$H_{Q W \max }:$ Maximum horizontal displacement of underground diaphragm wall $(\mathrm{mm})$

$H_{X D}$ : Relative horizontal displacement of diaphragm wall $(\mathrm{mm})$.

\section{Data Availability}

The data used to support the findings of this study are available from the first author upon request.

\section{Conflicts of Interest}

The authors declare that there are no conflicts of interest regarding the publication of this paper. 


\section{Acknowledgments}

This work was supported by the Key Research and Development Project of Shaanxi Province (No. 2021SF-523).

\section{References}

[1] Z. Liu, Loess Mechanics and Engineering, Shaanxi Science and Technology Press, China, 1997.

[2] Y. Zhang, Z. Song, X. Weng, and Y. Xie, "A new soil-water characteristic curve model for unsaturated loess based on wetting-induced pore deformation," Geofluids, vol. 2019, Article ID 1672418, 14 pages, 2019.

[3] Y. Xue, X. Zhang, S. Li et al., "Sensitivity analysis of loess stability to physical and mechanical properties: assessment model," International Journal of Geomechanics, vol. 19, no. 7, pp. 06019012.1-06019012.10, 2019.

[4] X. Wang, Y. U. Hongqin, C. Wang, and Y. Yang, "Study on control measures for subgrade settlement of high-speed railway in cold regions of western China," Subgrade Engineering, vol. 2017, no. 5, pp. 53-58, 2017.

[5] J. Qiu, Y. Qin, J. Lai et al., "Structural response of the metro tunnel under local dynamic water environment in loess strata," Geofluids, vol. 2019, Article ID 8541959, 16 pages, 2019.

[6] N. He, P. Li, S. Shao, J. Li, and Y. Jiao, "Ground settlement monitoring above Xi'an Metro tunnel through the saturated soft loess," Journal of Earth Sciences and Environment, vol. 34, no. 1, pp. 96-103, 2012.

[7] J. Yang, "Surface deformation induced by tunnel construction in saturated soft loess strata," Journal of Xi'an University of Science and Technology, vol. 38, no. 1, pp. 91-98, 2018.

[8] S. M. Haeri and A. A. Garakani, "Hardening behavior of a hydro collapsible loessial soil," in Proceedings of the 15th Asian Regional Conference on Soil Mechanics and Geotechnical Engineering, Fukuoka, Japan, November 2016.

[9] G. W. Clough, "Construction induced movements of in situ walls," Design \& Performance of Earth Retaining Structures, ASCE, Cornell, 1990.

[10] M. Long, "Database for retaining wall and ground movements due to deep excavations," Journal of Geotechnical and Geoenvironmental Engineering, vol. 127, no. 3, pp. 203-224, 2001.

[11] C. Moormann, "Analysis of wall and ground movements due to deep excavations in soft soil based on a new worldwide database," Soils and Foundations, vol. 44, no. 1, pp. 87-98, 2004.

[12] Y. Mei, Y.-L. Li, X.-Y. Wang, J. Wang, and C.-M. Hu, "Statistical analysis of deformation laws of deep foundation pits in collapsible loess," Arabian Journal for Science and Engineering, vol. 44, no. 10, pp. 8347-8360, 2019.

[13] J. Yang and D. Kong, "Deformation of deep and large foundation pit in soft soil of Fuzhou Subway," Arabian Journal of Geosciences, vol. 13, no. 2, 2020.

[14] Y. Mei, D. Zhou, X. Wang et al., "Deformation law of the diaphragm wall during deep foundation pit construction on lake and sea soft soil in the yangtze river delta," Advances in Civil Engineering, vol. 2021, no. 11, Article ID 6682921, 11 pages, 2021.

[15] Y. Zhou, X. Wang, Y. Zhu, and S. Gao, "Seepage Stability analysis of deep foundation pit of lanzhou metro under the condition of water level reduction in collapsible loess," China Railway Science, vol. 38, no. 1, pp. 86-94, 2017.

[16] J. Ren, J. Ma, J. Bai, and K. Yang, "Research on the deformation laws of center pillar of metro station excavated by semi-covered method," Journal of Railway Engineering Society, vol. 34, no. 9, pp. 103-108, 2017.

[17] M. Liu, D. Zhang, F. Qian, and Y. Hou, "Wall and ground movements due to deep excavation of tianjin subway station," DEStech International Conference on Transportation Infrastructure and Materials, vol. 2017, Article ID 9944, 2017.

[18] Z. Ding, J. Jin, and T.-C. Han, "Analysis of the zoning excavation monitoring data of a narrow and deep foundation pit in a soft soil area," Journal of Geophysics and Engineering, vol. 15, no. 4, pp. 1231-1241, 2018.

[19] Z. Li, M. Han, Y. Li, L. Yang, and W. Liu, "Analysis on continuous deformation process of underground continuous wall of foundation pit of daliang station," Chinese Journal of Underground Space and Engineering, vol. 15, no. S1, pp. 367-375, 2019.

[20] K. Elbaz, S.-L. Shen, Y. Tan, and W.-C. Cheng, "Investigation into performance of deep excavation in sand covered karst: a case report," Soils and Foundations, vol. 58, no. 4, pp. 1042-1058, 2018.

[21] G. Wang, W. Chen, and Q. Nie, "Impacts of pit excavation on foundation piles in deep silty soil by centrifugal model tests," Rock and Soil Mechanics, vol. 41, no. 2, pp. 399-407, 2020.

[22] J. Xu, S. Yang, H. Wu, and L. Zhang, "Monitoring and numerical analysis of pile-anchor supporting structure for deep and large foundation pit in loess area," Journal of Xi'an University of Architecture and Technology, vol. 51, no. 4, pp. 517-524, 2019.

[23] W. Zhang, H. Li, Y. Li, R. Zhang, and H. Liu, "Effects of jet grouting slabs on responses for deep braced excavations," Underground Space, vol. 6, no. 4, 2020.

[24] D. W. Zhang, J. C. Shu, and J. P. Sun, "Observed deformation characteristics of a deep excavation for the spring area in Jinan, China," Journal of Mountain Science, vol. 14, no. 3, 2017.

[25] H. Di, H. Guo, S. Zhou, J. Chen, and L. Wen, "Investigation of the axial force compensation and deformation control effect of servo steel struts in a deep foundation pit excavation in soft clay," Advances in Civil Engineering, vol. 2019, no. 6, Article ID 5476354, 16 pages, 2019.

[26] M. Farzi, M. S. Pakbaz, and H. A. Aminpour, "Selection of support system for urban deep excavations: a case study in Ahvaz geology," Case Studies in Construction Materials, vol. 8, pp. 121-138, 2018.

[27] C. Wang, D. Ling, and H. Wang, "Influence of soft clay structure on pit excavation and adjacent tunnels," Journal of Zhejiang University, vol. 54, no. 2, pp. 264-274, 2020.

[28] C. Liu, F. Ji, G. Zheng, T. Liu, and Y. Liu, "Measurement and mechanism of influences of rainfall on supporting structures of foundation pits in soft soils," Chinese Journal of Geotechnical Engineering, vol. 42, no. 3, pp. 447-456, 2020.

[29] Y. M. A. Hashash, A. Osouli, and C. Marulanda, "Central artery/tunnel project excavation induced ground deformations," Journal of Geotechnical and Geoenvironmental Engineering, vol. 134, no. 9, pp. 1399-1406, 2008.

[30] R. B. Peck, "Deep excavations and tunneling in soft ground," in Proceedings of the 7th International Conference on Soil Mechanics and Foundation Engineering, Mexico, 1969.

[31] A. I. Mana, "Prediction of movements for braced cuts in clay," Geotechnical Engineering, vol. 107, 1981.

[32] C.-Y. Ou, P.-G. Hsieh, and D.-C. Chiou, "Characteristics of ground surface settlement during excavation," Canadian Geotechnical Journal, vol. 30, no. 5, pp. 758-767, 1993.

[33] J. H. Wang, Z. H. Xu, and W. D. Wang, "Wall and ground movements due to deep excavations in shanghai soft soils," 
Journal of Geotechnical and Geoenvironmental Engineering, vol. 136, no. 7, pp. 985-994, 2010.

[34] H. Xiao, S. Zhou, and Y. Sun, "Wall deflection and ground surface settlement due to excavation width and foundation pit classification," KSCE Journal of Civil Engineering, vol. 23, no. 4, pp. 1537-1547, 2019. 